\title{
Effect of Cryogenic Treatment on Properties of Cemented Carbides
}

\section{Vojtěch Průcha, David Bricín, Antonín Kř́iž}

Faculty ofMechanical Engineerign, University of West Bohemia. Univerzitní 22, Pilsen 306 14, Czech Republic. E-mail: vprucha@kmm.zcu.cz, bricda@kmm.zcu.cz, kriz@kmm.zcu.cz

The main goal of this paper is to present experiments exploring the effect of cryogenic treatment on the properties of cemented carbides. The experimental materials were chosen from three basic groups of cemented carbides with different binders and different WC grain sizes. One half of the specimens were cryogenically-treated, whereas the other half were in the as-received condition. The specimens were ground and polished using metallographic procedures. Effects of cryogenic treatment were studied by metallographic observation using light and scanning electron microscopes, by $\mathrm{X}$-ray analysis of phase composition and by measuring Vickers hardness and $K_{I C}$ fracture toughness. It was found that residual stresses in specimen surface decreased after cryogenic treatment. The $K_{I C}$ fracture toughness of the specimens increased.

Keywords: Cryogenic Treatment, Cemented Carbide, Residual stress, Hardness, Phase Analysis

\section{Introduction}

Cemented carbides (CC) are best known as cutting tool materials. The reason for their use is that they contain hard tungsten carbide (WC) particles and a binder phase (most often cobalt) which provides toughness. Tungsten carbide provides sufficient hardness and wear resistance. By choosing the right combinations of binder and carbides, one can effectively control the properties and field of application of the particular product. The properties and applicability of a cemented carbide depend not only on its phase composition but also on its coating and heat treatment. [1-2]

According to current articles on heat treatment of cemented carbide tools, cryogenic treatment can extend their life and improve their wear resistance by up to several tens of percent [3-4].

Tab. 1 Cemented carbides used for making the specimens

\begin{tabular}{|c|c|c|c|}
\hline $\begin{array}{c}\mathrm{CC} \\
\text { type }\end{array}$ & $\begin{array}{c}\text { Grain size } \\
(\mu \mathrm{m})\end{array}$ & $\begin{array}{c}\text { Binder } \\
\text { type }\end{array}$ & $\begin{array}{c}\text { Binder content } \\
(\text { wt. \%) }\end{array}$ \\
\hline $\mathrm{A}$ & $0.5-0.8$ & $\mathrm{Co}$ & 12 \\
\hline $\mathrm{B}$ & $0.5-0.8$ & $\mathrm{Ni}$ & 12 \\
\hline $\mathrm{C}$ & $3-9$ & $\mathrm{Co}$ & 10 \\
\hline
\end{tabular}

This paper presents the results of experiments assessing the suitability of this heat treatment method for three types of cemented carbides. The differences between them were in the carbide grain size and in the binder type and content, as detailed in Tab. 1.

One half of these specimens were cryogenically treated whereas the rest remained in the as-received condition. The specimens were cryogenic processed by European Cryogenic Institute s.r.o. Prior to analysis, the specimens were ground and polished metallographically. The purpose of the metallographic analysis was to identify microstructural differences between cryogenicallytreated and as-received specimens. Their mechanical properties were determined using Vickers hardness measurement and by calculating fracture toughness according to Palmqvist [4-5]. Phase composition was determined by $\mathrm{X}$-ray analysis. Residual stress levels were measured in the specimens.

\section{Results and discussion}

\subsection{Metallographic examination and phase analysis}

The goal of the metallographic analysis was to determine volume fractions of phases on metallographic sections in cryogenically-treated and as-received specimens in accordance with ASTM B657 - 92 standard [6]. ๆ-phase and $\alpha$-phase were highlighted using the Murakami reagent. $\gamma$-phase was revealed using Murakami and an aqueous solution of hydrochloric acid. The etching times were between 2 seconds and 6 minutes, depending on the phase of interest. Figs. 1-3 below show micrographs of cryogenically-treated and as-received specimens. Fig. 4 gives the results of phase analysis.

No $\eta$-phase was found by metallographic examination using a Zeiss-Observer $\mathrm{Z} 1 \mathrm{~m}$ light microscope in $\mathrm{A}-\mathrm{C}$ specimens prior to or after cryogenic treatment, Fig. 1. No other types of $\gamma$-phase carbides were found either, Fig. 2. The fact that the specimens only contained $\alpha$-phase, i.e. tungsten carbides (WC), and $\beta$-phase, i.e. Co or Ni binder, was confirmed by X-ray phase analysis, Fig. 4.

This indicates that cryogenic treatment leads to no distinct changes in the structure, which is in agreement with published studies [7-8]. These studies explained the main cause of the enhanced wear resistance of cemented carbides as structural changes in the binder. Specifically, according to them, it was an increase in the fraction of $\eta$ phase. However, this phase was not found in the present specimens. If its volume in these specimens indeed changed, it was lower than the detection limit of the X-ray equipment used and lower than the resolution limit of the light microscope. The other cause reported in studies is coarsening and spheroidisation of WC grains due to selfdiffusion of carbon on the WC-cobalt interface. However, this phenomenon is impossible to detect by metallographic analysis. Nevertheless, it can be expected to play a more important role in fine-grained grades with higher free energy levels, which is why their carbide grains should spheroidise more readily as a result of cryogenic treatment. 


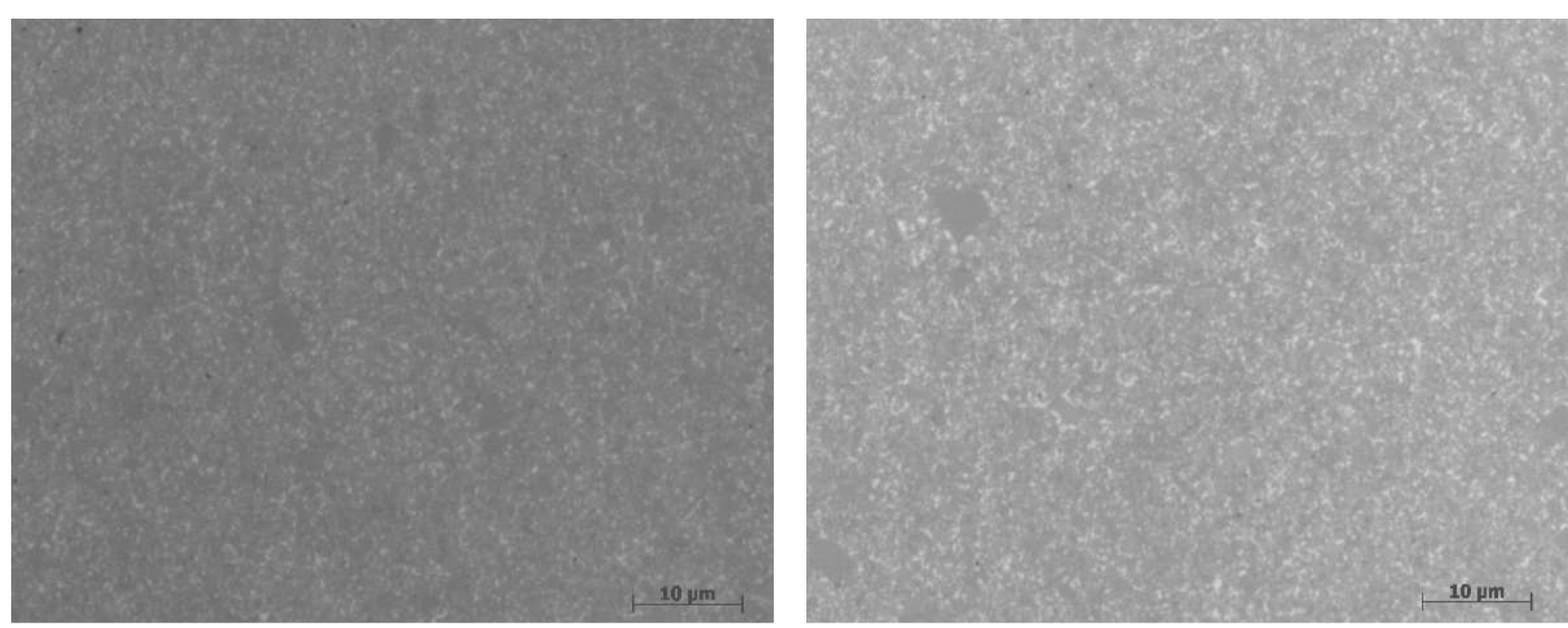

Fig. 1 Microstructure of cryogenically-treated (right) and as-received (left) specimen A. The focus was on $\eta$-phase. The etching colours $\eta$-phase brown-orange, magnification $1000 \times$
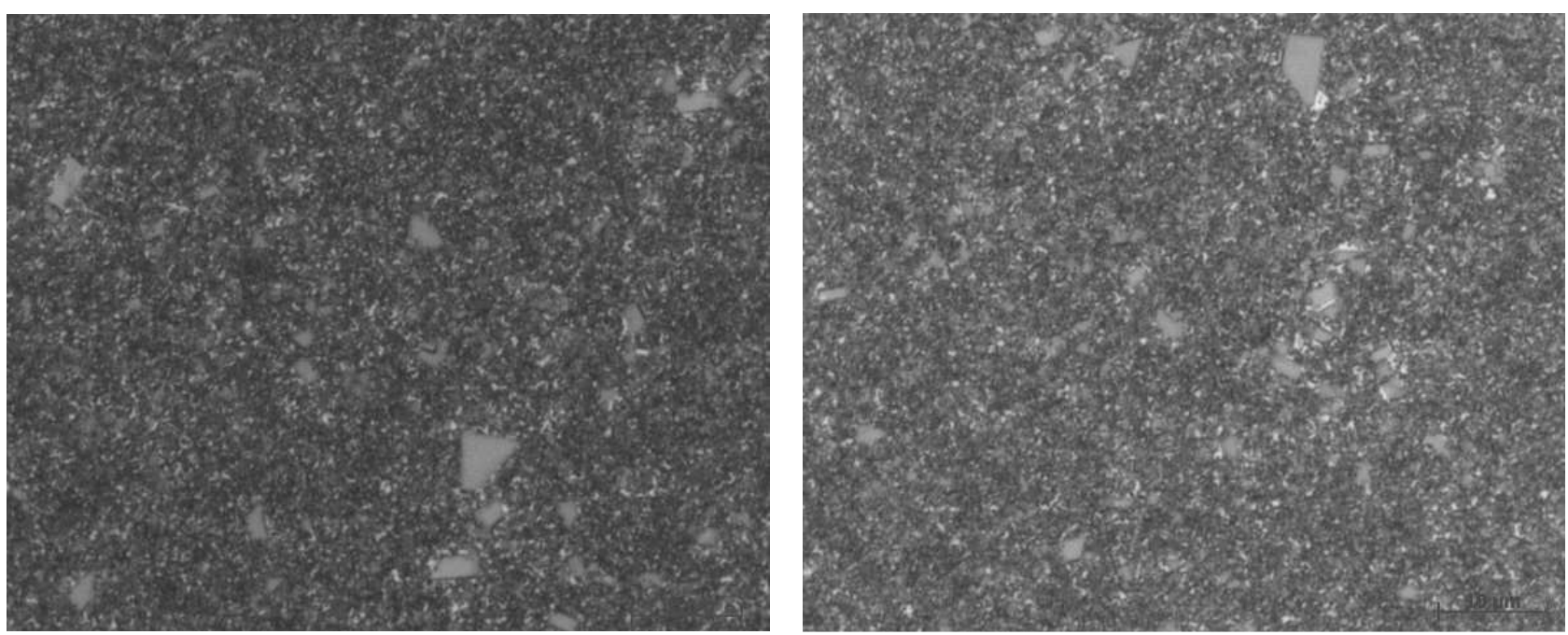

Fig. 2 Microstructure of cryogenically-treated (right) and as-received (left) specimen A. The focus was on $\gamma$-phase. The etching colours $\gamma$-phase brown-yellow, magnification $1000 \times$
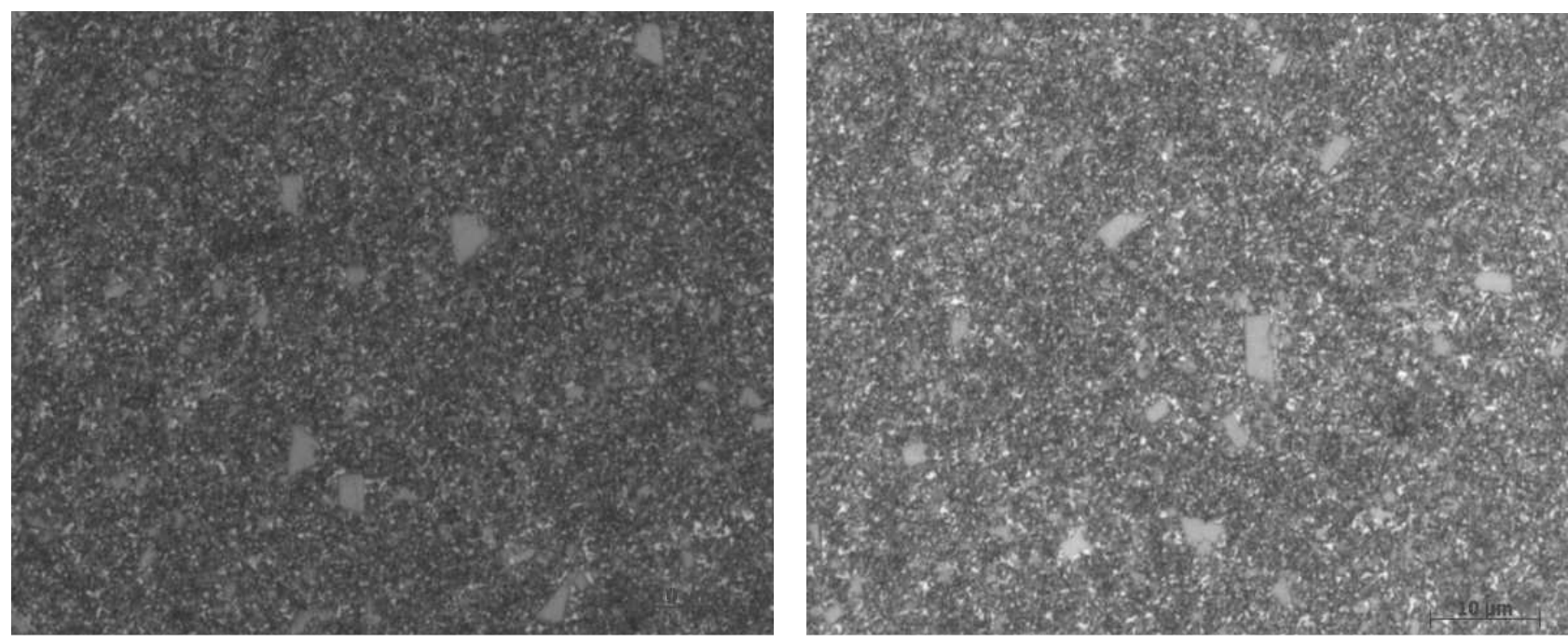

Fig. 3 Microstructure of cryogenically-treated (right) and as-received (left) specimen A. The focus was on $\alpha$-phase and $\beta$-phase. The etching colours $\alpha$-phase grey and $\beta$-phase white, magnification $1000 \times$ 


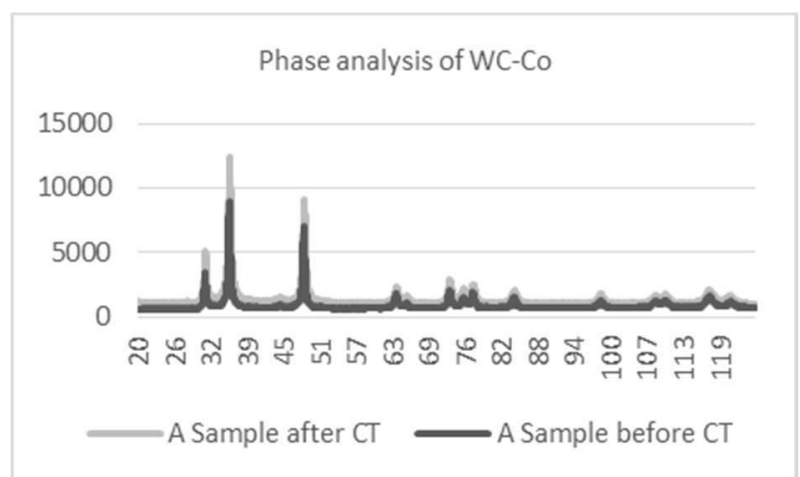

Fig. $4 X$-ray phase analysis of a specimen of cemented carbide A. Phase composition was analysed before and after cryogenic treatment

\subsection{Analysis of residual stress}

The goal was to assess the evolution of residual stresses in cemented carbides as a result of cryogenic treatment.

The measurement was carried out using a theta-theta goniometer X'Pert PRO MPD from PANalytical. An Xray source with a cobalt anode and crossed grids of $2 \times 1$ $\mathrm{mm} 2$ size were used. Eleven $\psi$ angle values were employed, i.e. $\sin ^{2} \psi=0-0.5$ varied in steps of 0.1 , for both positive and negative angle values. The $\{112\}$ diffraction line of the hexagonal-structure WC phase was analysed. The results are given in Table 2 and Figure 5.

Tab. 2 Measured residual stresses in cryogenically-treated and as-received specimens

\begin{tabular}{|c|c|c|c|c|}
\hline \multirow{2}{*}{$\begin{array}{c}\text { CC } \\
\text { type }\end{array}$} & \multicolumn{2}{|c|}{ As-received specimens } & \multicolumn{2}{c|}{ Cryogenically-treated specimens } \\
\cline { 2 - 5 } & $\begin{array}{c}\text { Longitudinal di- } \\
\text { rection }\end{array}$ & Transverse direction & Longitudinal direction & Transverse direction \\
\hline A & $-2399 \pm 90$ & $-2389 \pm 112$ & $-2011 \pm 86$ & $-1949 \pm 75$ \\
\hline B & $-1917 \pm 44$ & $-1766 \pm 92$ & $-1359 \pm 55$ & $-1566 \pm 82$ \\
\hline C & $-1443 \pm 90$ & $-981 \pm 78$ & $-1364 \pm 54$ & $-1112 \pm 46$ \\
\hline
\end{tabular}

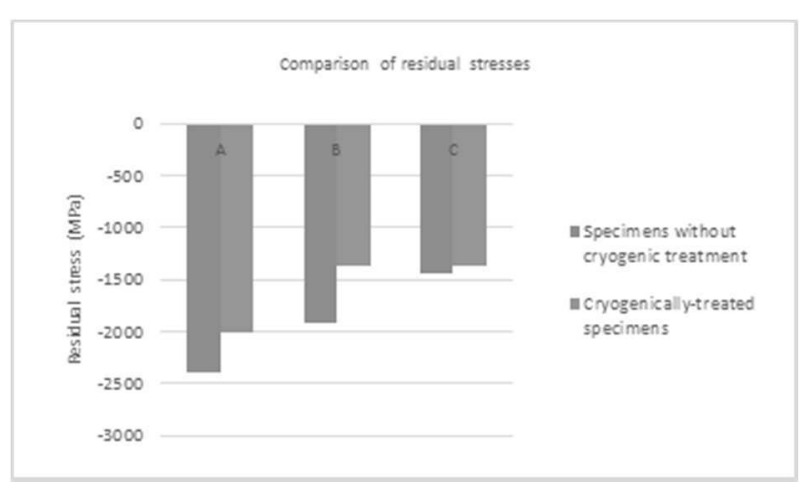

Fig. 5 Calculated residual stress levels

It follows from the above graph that residual stresses were relieved in all types of cemented carbides during cryogenic treatment. The differences in stress levels in asreceived specimens arose mainly from the cemented carbide chemical composition and WC grain size.

Authors of specialist papers offer different opinions on post-cryogenic treatment residual stresses. Some studies reported an increase in residual stress levels [9-10] whereas others mentioned the opposite [8]. The reason is that each of these studies used a different cryogenic treatment method, i.e. different heating and cooling rates, temperatures and times at temperature. Besides, specimen preparation plays a significant role as well. Rough grinding as well as cryogenic treatment substantially alter the residual stress.

\subsection{Mechanical properties}

Hardness was measured by means of the DuraScan 50 automatic hardness tester from Struers. Fracture toughness was calculated using the Palmqvist relationship: see Equation 1-2 below[5].

$$
\begin{gathered}
\mathbf{W}_{\mathrm{g}}=\frac{\mathbf{P}}{\mathbf{T}} \\
\mathbf{W}_{\mathbf{K}}=\mathbf{A} \cdot \sqrt{\mathbf{H V}} \cdot \sqrt{\mathbf{W}_{\mathrm{g}}}\left[\mathrm{MN} / \mathbf{m}^{3 / 2}\right]
\end{gathered}
$$

Where:

$\mathrm{P}$ stands for the indentation load; $\mathrm{T}$ is the total length of cracks; A is a constant equal to 0.028 ; and HV is Vickers hardness

HV30 macrohardness was measured and used for calculating the fracture toughness $\mathrm{K}_{\mathrm{IC}}$. In addition, HV0.1 microhardness was measured which was expected to reflect more accurately the microstructural changes related to cryogenic treatment. Macrohardness, microhardness and fracture toughness values are given in Table 3 and Figs. 6-7. Indents and cracks produced during Vickers hardness testing were measured using a PHILIPS ESEM electron microscope and magnifications of $1500-3500 \times$.

Tab. 3 HV3O and HV0.1 hardness and fracture toughness of cemented carbides

\begin{tabular}{|c|c|c|c|c|c|c|}
\hline \multirow{2}{*}{ Sample } & \multicolumn{3}{|c|}{ As-received specimens } & \multicolumn{3}{c|}{ Cryogenically-treated specimens } \\
\cline { 2 - 8 } & Hardness, HV30 & $\begin{array}{c}\text { Hardness, } \\
\text { HV0.1 }\end{array}$ & K IC(Palmqvist) & $\begin{array}{c}\text { Hardness, } \\
\text { HV30 }\end{array}$ & $\begin{array}{c}\text { Hardness, } \\
\text { HV0.1 }\end{array}$ & K IC(Palmqvist) \\
\hline A & $1596 \pm 33$ & $1703 \pm 78$ & $10.5 \pm 0.1$ & $1638 \pm 34$ & $1847 \pm 55$ & $10.8 \pm 0.1$ \\
\hline B & $1530 \pm 23$ & $1675 \pm 104$ & $11.6 \pm 0.3$ & $1523 \pm 20$ & $1667 \pm 53$ & $12.3 \pm 0.3$ \\
\hline C & $1217 \pm 9$ & $1528 \pm 117$ & $17.4 \pm 0.5$ & $1183 \pm 20$ & $1469 \pm 118$ & $25.9 \pm 3.6$ \\
\hline
\end{tabular}



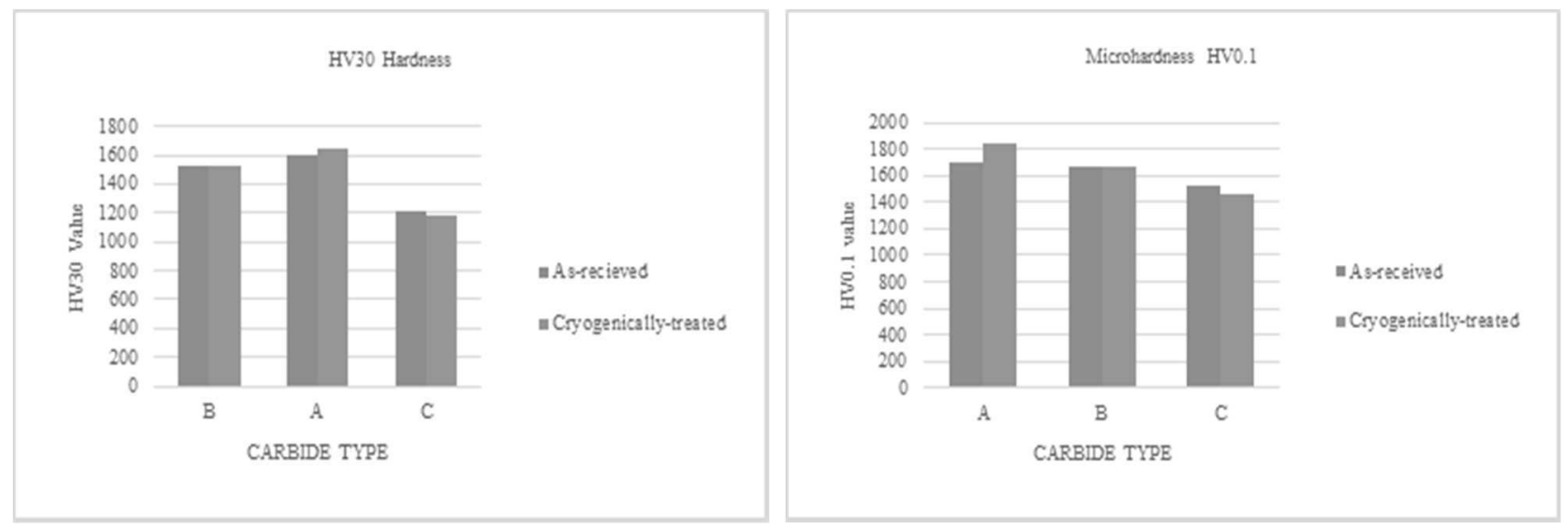

Fig. 6 HV3O and HVO.1 hardness of cryogenically-treated and as-received specimens. The graph on the left shows measured HV3O hardness values and the one on the right contains HVO.1 values

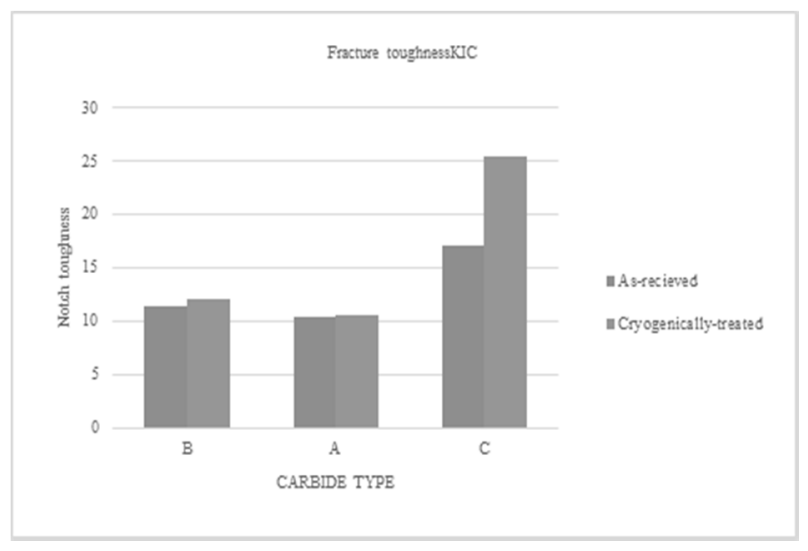

Fig. 7 Fracture toughness $K_{I C}$ of cryogenically-treated and as-received specimens

Specimens of B and $\mathrm{C}$ types showed a decrease in hardness after cryogenic treatment. Type A exhibited an increase in hardness. This was confirmed by microhardness testing, see Fig. 6.

It is likely that the decrease in hardness of $\mathrm{B}$ and $\mathrm{C}$ specimens was related to a relief of residual stresses in the course of cryogenic treatment.

In addition, the measurement of hardness was probably influenced by evolution of various types of microstructures during cryogenic treatment. As mentioned above, hardness may also depend on the volume fraction of $\eta$-phase. The region in which this phase primarily forms is linked to the carbide-binder interface. In fine-grained cemented carbides, the interface area between the binder and tungsten carbides is larger which means that the region in which carbon may diffuse into the binder is expanding. In coarse-grained type $\mathrm{C}$ specimens, the growth of $\eta$-phase could not have been as extensive because the contact surface between carbide grains and binder was smaller. By contrast, $\eta$-phase was expected to form in cryogenically-treated fine-grained cemented carbide A. However, this was not confirmed by either phase analysis or metallographic observation. Hence, there was no contribution from this phase to the increase in hardness. In type B specimens whose binder consisted of nickel, hardness did not increase because of the low solubility of carbon in nickel, see Fig. 8.
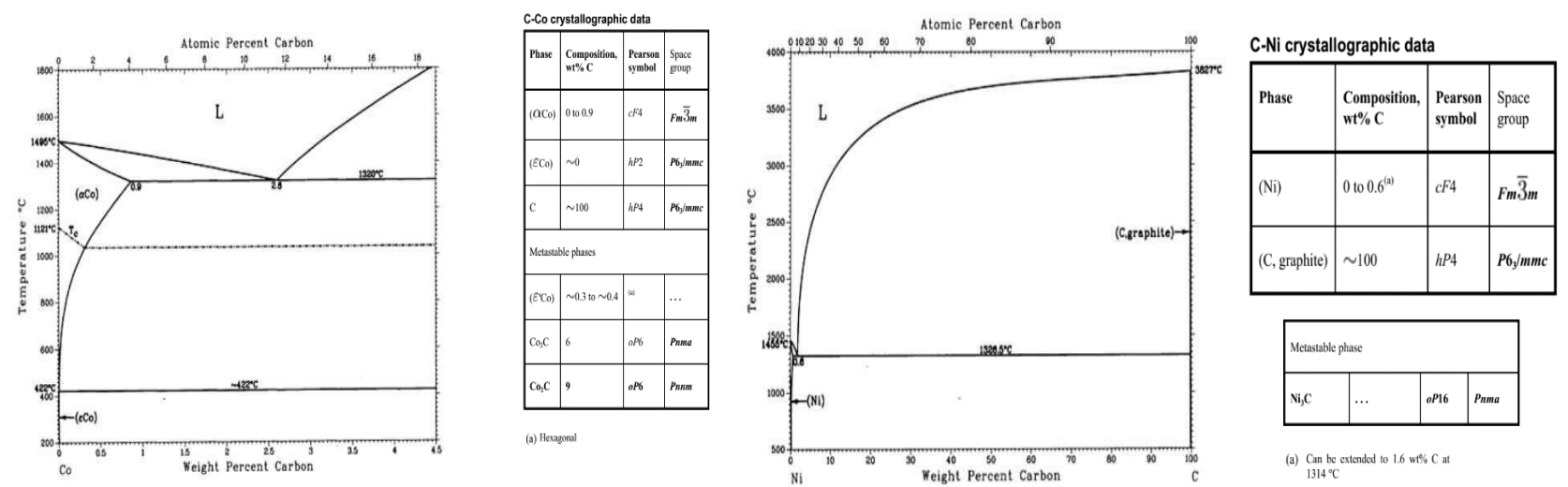

(a) Can be cxended to $1.6 \%$ w\% C at

Fig. $8 \mathrm{Co}$-C and Ni-C binary diagrams. The Co-C binary diagram is on the left. The Ni-C binary diagram [11] is on the right

In this type of cemented carbide, hardness might have been affected by formation of a Ni-C eutectic on the interface between WC grains and Ni binder. This newlyformed phase might have reduced both residual stress and hardness levels.

Another factor reported by the studies as the cause of an increase in hardness upon cryogenic treatment is shear (martensitic) transformation of high-temperature face- 
centred cubic $\alpha$-Co phase to hexagonal $\varepsilon$-Co. The $\varepsilon$-Co phase exists below $422^{\circ} \mathrm{C}$, see Fig. 8 . It has higher hardness and wear resistance than $\alpha$-Co. The above-cited studies reported that the fraction of newly-formed $\varepsilon$-Co depended on the volume percentage of cobalt. At lower cobalt contents, the volume fraction of newly-formed $\varepsilon-\mathrm{Co}$ was higher. [9]

Despite that, the coarse-grained type B which had a lower binder content than the other CC types did not exhibit the expected increase in hardness. This is related to the fact that the interparticle spacing, which is the distance between tungsten carbide grains, is larger in this type than in the $\mathrm{A}$ and $\mathrm{C}$ types. For this reason, the formation of new $\varepsilon$-Co phase in this cemented carbide type could not have been as intensive as in the fine-grained type A carbide.

In all types of cemented carbides (A-C), fracture toughness $\mathrm{K}_{\mathrm{IC}}$ increased as a result of cryogenic treatment, see Fig. 7.

This can be explained by the fact that residual stresses were relieved during cryogenic treatment. At room temperature, carbide grains are subjected to compressive stress exerted by the binder. [4] By contrast, the binder is under tensile stress. A decrease in compressive stress is a result of a decrease in tensile stress in the binder. This phenomenon enhances the toughness of the binder, and thereby hinders propagation of cracks which initiate at the carbide grain-binder interface during hardness testing.

\section{Conclusion}

Based on these experiments, it can be stated that cryogenic treatment significantly affects the behaviour and properties of cemented carbides.

It was found that an appropriate method of cryogenic treatment can increase their fracture toughness value $\left(\mathrm{K}_{\mathrm{IC}}\right)$. It was proven that residual stress levels can be reduced.

Furthermore, it was found that the formation of the $\varepsilon$ Co phase does not depend solely on the volume fraction of the binder in a cemented carbide but also on interparticle spacing, a parameter which indicates the distance between carbide grains. Interparticle spacing depends on both binder content and carbide grain size.

Metallographic examination of the specimens did not provide evidence of the presence of $\eta$-phase or $\gamma$-phase before or after cryogenic treatment. Changes in the phase composition or presence of the above phases were not confirmed by X-ray phase analysis either.

Microhardness testing, however, indicated certain microstructural changes in the fine-grained type A carbide. It has shown that cryogenic treatment caused cemented carbide A to develop higher hardness despite a decrease in residual stress levels. Those stresses also affect this measurement, as manifested in B and C type specimens.

The next phase of this study will involve experiments whose purpose will be to explore the ways in which cryogenic treatment affects tribological properties of cemented carbides and, ultimately, the cutting properties of cutting tools, particularly the life of the cutting part of a tool.

\section{Acknowledgement}

This paper is a result of the student project no. SGS2016-036 entitled "Analysis, development and modification of technologies of treatment of bulk advanced materials for power generation machines, transport equipment and related engineering applications".

\section{References}

[1] HUMAR, Anton. (2008). Materials for cutting tools. Praha: MM Publishing, 2008. ISBN 978-80254-2250-2.

[2] EDITOR-IN-CHIEF VINOD K. SARIN a Luis LLanes EDITED BY DANIELE MARI. (2014). Comprehensive hard materials. Elsevier, 2014. ISBN 9780080965284.

[3] YONG, A. Y. L., K. H. W. SEAH a M. RAHMAN. (2007). Performance of cryogenically treated tungsten carbide tools in milling operations. The International Journal of Advanced Manufacturing Technology [online]. 2007, 32(7-8), 638-643 [cit. 2018-02-12]. DOI: 10.1007/s00170005-0379-0. ISSN 0268-3768. Available from: http://link.springer.com/10.1007/s00170-0050379-0

[4] SHREYAS, T. DHANDEL, VIJAY A. KANE2, CHANDRASHEKHAR L. GOGTE. (2014). Cryogenic Treatment of Tungsten Carbide Tools: Review. International Journal of Science and Research (IJSR). Volume 3 Issue 11, November 2014. [cit.2018-02-12]. ISSN (Online): 23197064. Available from: https://www.ijsr.net/archive/v3i11/U1VCMTQxMTA=.pdf

[5] SPIRIT, ZBYNEK. (2013). Selected Properties and Cutting Tool Applications of Sintered Carbides. Diploma thesis. University of West Bohemia in Pilsen. 2013. [Cit. 2018-02-12]. Available from: http://hdl.handle.net/11025/8624.

[6] ASTM B657-92(1996)e1. Standard Test Method for Metallographic Determination of Microstructure in Cemented Tungsten Carbides. ASTM International. West Conshohocken. PA. 2000.

[7] HEN-HUI, XIE. JI-WU, HUANG. YUN-FENG, TANG. LI-NING, GU. (2015). Effects of deep cryogenic treatment on microstructure and properties of WC-11Co cemented carbides with various carbon contents. Transactions of Nonferrous Metals Society of China. Volume 25. Issue 9. 2015. Pages 3023-3028. ISSN 1003-6326., https://doi.org/10.1016/S1003-6326(15)63929-2. http://www.sciencedirect.com/science/article/pii/S1003632615639292

[8] SWAMINI A. CHOPRA, V.G. SARGADE, (2015). Metallurgy behind the Cryogenic Treatment of Cutting Tools: An Overview. Materials Today: Proceedings. Volume 2. Issues 4-5. 2015. 
Pages 1814-1824. ISSN 2214-7853. https://doi.org/10.1016/j.matpr.2015.07.119. http://www.sciencedirect.com/science/article/pii/S2214785315003648

[9] HEJIA, ZHANG. LIQING, CHEN. JING, SUN. WENGUANG, WANG. QUANZHAO, WANG. (2015). An investigation of cobalt phase structure in WC-Co cemented carbides before and after deep cryogenic treatment. International Journal of Refractory Metals and Hard Materials. Volume 51. 2015. Pages 201-206. ISSN 0263-4368. https://doi.org/10.1016/j.ijrmhm.2015.04.007.http://www.sciencedirect.com/science/article/pii/S0263436815300032

[10] JIANG, YONG. CHEN, DING. (2011). Effect of cryogenic treatment on $\mathrm{WC}-\mathrm{Co}$ cemented carbides. Materials Science and Engineering. A, Volume 528. 2011. Pages 1735-1739. ISSN 09215093.

https://doi.org/10.1016/j.msea.2010.11.009.http:// www.sciencedirect.com/science/article/pii/S0921509310012967
[11] ASM HANDBOOK. 10th editon. Materials Park, Ohio: ASM International, 2016. ISBN 0-87170381-5.

[12] KŘÍŽ, A., BRICÍN, D., PRŮCHA, V. (2018). The Potential for Heat Treating Cemented Carbides. Manufacturing Technology. Volume 18. 2018. Pages 600-604. ISSN 1213-2489

[13] ŤAVODOVÁ, M., KALINCOVÁ, D. (2016). The Research of Options for the Innovation Heat Treatment of the Tools for Coinage in Order to Increase their Lifetime. Manufacturing Technology. Volume 16. 2016. Pages 274-280. ISSN 12132489

[14] MAJERÍK, J., BARÉNYI, I. (2018). Wear and Tool Life Investigation of Carbide Inserts while Hard Machining of Armox 500 Steel. Manufacturing Technology. Volume 18. 2018. Pages 273278. ISSN 1213-2489. 